\title{
Prevalence and Associated Factors of Hypertension in Hirat City Afghanistan, 2015
}

\author{
Khwaja Mir Islam Saeed (MD, MSc) ${ }^{1}$ \\ ${ }^{1}$ Head of Grant and Service Contract Management Unit (GCMU), Ministry of Public Health, Kabul- \\ Afghanistan, Tel: 0093700290955
}

\begin{abstract}
Background: Hypertension is one of the most common causes of premature death and morbidity in both developed and developing countries. The aim of this study is to determine the prevalence of hypertension and characterize associated risk factors in an urban setting in Afghanistan.

Methods and Materials: A provincial-based cross-sectional study was conducted in May-June 2015 among 1129 adult residents of Hirat city using the World Health Organization STEP wise approach tool (WHO STEPS). A multi-stage sampling technique was used to enroll participants in the study. Socio-economic and demographic variables were collected via face to face interviews, after which blood samples were collected using a locally developed standard operating procedure (SOP). Bivariate and multivariable analyses were performed to explore the association and data were coded, entered, and analyzed with SPSS version 20 software package.

Results: A total of 1129 responses $(47.4 \%$ males, $52.6 \%$ females) of $25-70$ years of age were included in the analysis. The overall prevalence of hypertension was $35.6 \%$. Mean systolic blood pressure and standard deviation (SD) was $123.4 \pm 18.5 \mathrm{mmHg}$ and mean diastolic blood pressure was $81.8 \pm 13 \mathrm{mmHg}$. Overall, $3.6 \%$ of hypertensive participants were previously diagnosed or were under treatment. According to the multivariate logistic regression analysis, age, central obesity, general obesity and existing of diabetes mellitus were statistically significant predictors of hypertension.

Conclusion: One third of adults are suffering from hypertension while $32 \%$ were latent. Age, obesity, and diabetes were identified as risk factors. However mass screening for hypertension, health education and life style modifications are recommended.
\end{abstract}

Keywords: prevalence, associated factors, hypertension, urban, Afghanistan

\section{INTRODUCTION}

Non-communicable diseases (NCDs) are a leading cause of death worldwide [1]. About 38 million people die every year due to non-communicable disease of which more than two third occur in low and middleincome countries [2]. Hypertension (HTN), as a NCD, is a global public health problem, affecting approximately one billion people worldwide and that is predicted to increase to 1.5 billion by the year 2025 [3]. The global prevalence of HTN is approximately $30 \%$ among adults; in developed countries, prevalence is beginning to stabilize or decrease, while in the developing regions, proportions continue to rise (between 20$50 \%)[4,5]$. According to findings and literature the common risk factors reported associated with HTN are genetics, family history, advanced age, race, obesity, physical inactivity, lifestyle, cigarette smoking, excessive salt and alcohol intake, and dietary habits [6-9]. Furthermore HTN prevalence has been reported to be 15-35\% in Asia [10] 20-33\% in Africa, [11] 18-22\% in the USA, [12] 44\% in some European countries, [12] $44 \%$ in Turkey, [6] 26.3\% in Egypt, [13] 32.2\% in India, [14] and 32.1\% in Qatar [15].

In the Eastern Mediterranean Region (EMR), the prevalence of HTN has been estimated to be 29\%, affecting approximately 125 million individuals [16].Afghanistan is part of EMR but due to years of war and conflict, few studies conducted to estimate the burden of NCD including hypertension. According to our previously published study of chronic disease risk factors in Kabul, in a sample of individuals aged 40+, the overall prevalence of obesity, HTN, and diabetes mellitus was $31.2 \%, 46 \%$, and $13.3 \%$, respectively [17]. Furthermore another study showed that the prevalence of hypertension in Jalalabad city, an eastern province of Afghanistan, was $28.4 \%$ [18]. In neighboring countries such as Iran and Pakistan, the overall prevalence of HTN in the adult population was 23\% and 26\% respectively [19-20]. In addition, the Afghan Mortality Survey (AMS 2010 ) indicated that $35 \%$ of all-cause mortality in Afghanistan is due to non-communicable disease, particularly cardiovascular disease and cancer [21]. As of 2016, Afghanistan suffers from lack of reliable information on the burden of non-communicable disease, including HTN, due to the fact that high priority is given to infectious diseases. The purpose of this study is to estimate the burden of HTN and associated risk factors among the adult population in Afghanistan's western city, Hirat. It will provide evidence to support strategic decisions such as 
resource allocation and public health interventions to reduce risk factors and decrease the burden of disease in the country.

\section{METHODS AND MATERIALS}

The research team conducted a provincial cross-sectional study from May to June 2015 using the WHO STEP-wise approach [22] to estimate the prevalence and factors for non-communicable diseases in Hirat city, Afghanistan. STEPS was initiated by the WHO to establish the surveillance of risk factors for noncommunicable diseases. The survey tool collects information on behavioral, physical, and biochemical measurements as a part of the core, expanded, and optional modules.

\section{Study Setting:}

Hirat is a province in western border of Afghanistan and the study conducted in urban setting of the province (Hirat City). The 2015 Expanded Programme for Immunization (EPI) list of clusters was used as the sampling frame. Using multi-stage cluster sampling, in the first stage we conventionally and randomly selected 16 out of 60 EPI cluster. In the second stage, from each selected cluster five areas (Called Area/Guzar) were randomly selected, and finally the overall sample of 1200 households distributed among these selected area according to the proportion to the size of household number in each cluster / areas. Taking into account the number of households in each area, the households were selected using systematic random sampling. Inclusion criteria included: ages 25-70 (adult population, as outlined in WHO survey tool), city residents during study period, and consent to participate. Exclusion criteria included: temporary residents (less than six months) and those living in institutionalized settings or in unsafe areas were excluded from the study.

\section{Study Population:}

Initially the purpose of the study shared with community representatives and later on the team approached 16 clusters and five areas of EPI. Our primary sampling unit (PSU) was clusters, secondary sampling units (SSU) were streets/areas, tertiary sampling units (TSU) were households, and ultimate sampling units (USU) were respondents more than 25 years of age in the household. The interviewer was instructed to find the masjid as a fixed landmark or a very populated street within the boundaries of the selected location and, following the bottle rotating rule, proceed to series of households. The survey team were consist of male and female to observe the cultural sensitivity of society.

\section{Measures:}

The WHO STEPS was used to collect demographic, socio-economic, clinical, and behavioral data via face-to-face interviews. Weighing scales and tension tape were used to measure body weight and height. A body mass index (BMI, hereafter reported without units) $\geq 30 \mathrm{~kg} / \mathrm{m} 2$ was considered as obese, 25-29.9 was considered as overweight, and 18.5-24.9 was considered normal weight [23]. A waist circumference $\geq 94 \mathrm{~cm}$ for men and $\geq 80 \mathrm{~cm}$ for women was considered as central obesity [24]. Cuff type sphygmomanometers were used to measure systolic and diastolic blood pressure (BP) thrice with five minutes between each measurement at a sitting or lying position by our trained surveyors. Systolic blood pressure levels $\geq 140 \mathrm{mmHg}$ and/or diastolic pressure levels $\geq 90 \mathrm{mmHg}$ were considered hypertensive [25]. HTN in this study was defined as having a previous diagnosis of HTN or having a BP of HTN status. Blood samples were collected and processed by lab technicians under supervision of the lab coordinator. After shipment of samples to the Central Public Health Laboratory (CPHL) in Kabul, they were stored at $-80^{\circ} \mathrm{C}$ until glucose measurement was completed. For enhancing quality of data close monitoring carried out throughout all processes.

\section{Statistical Considerations:}

Epi Info version 7[26] were used for data entry and analyses were performed using IBM SPSS software version 20 [27]. As data regarding risk factor prevalence in this province were not available, we assumed the highest prevalence and 95\% confidence interval and band of error of 5\%. To balance considerations of nonresponse rate, cost, resources, and time without compromising the representativeness of the sample, a two-phase cluster sampling technique was used. The sample size was calculated to be able to determine the effect of risk factors on non-communicable diseases. The resulting sample size was 1,200. Participants with missing main data and specimen were excluded from the final analysis, which incorporated 1,129 participants. Chi-square and logistic regression was used to examine the association of relevant variables at univariate and multivariate levels.

\section{Ethical consideration:}

For this study a general approval was given by the institutional review board (IRB) of the Ministry of Public Health and informed consent was taken from each individual before the interview. The results of physical and biochemical measurements communicated to required participants and the confidentiality of the information 
gathered was maintained. All blood samples were stored under $-80^{\circ} \mathrm{C}$ in $\mathrm{CPHL}$ after completing biochemical measurements for further testing. It is planned to conduct further biochemical studies over the samples which is stored in CPHL.

\section{Descriptive Analysis:}

\section{RESULTS}

A total of 1,129 adults (47.4\% males, $52.6 \%$ females) of $25-70$ years of age were surveyed. The average age of this sample was $41.5 \pm 13.1$ years. The overall prevalence of HTN was $35.6 \%$ among the age group of 25-70 years. Mean systolic blood pressure and standard deviation (SD) was $123.4 \pm 18.5 \mathrm{mmHg}$ and ranged from 80 to $196.7 \mathrm{mmHg}$. Mean diastolic blood pressure was $81.8 \pm 13 \mathrm{mmHg}$ and ranged from 40 to 140 mmHg. Overall, $3.6 \%$ of hypertensive participants were previously diagnosed or were under treatment for HTN, which is very low and could be due to latent HTN or asymptomatic HTN. More than half of the respondents (54\%) were illiterates, and $82.7 \%$ of participants had a monthly income < 10000 Afghanis (USD146). Majority of the study participants were married $(85.8 \%$ ), while more than $80 \%$ of women were housewives. (Refer to Table 1 for details on demographic variables). The mean height, weight, and waist circumference were $162 \mathrm{~cm}$, $66.6 \mathrm{~kg}$, and $87 \mathrm{~cm}$ respectively. The mean and SD of body mass index was $25.4 \pm 5.3 \mathrm{~kg} / \mathrm{m} 2$. Descriptive statistics demonstrated that $5.6 \%$ were current smokers and half of smokers had duration of 10 years or more while twice of that $(10.8 \%)$ were mouth snuff users. Around $45 \%$ of respondents reported to use liquid oil for cooking in their kitchen. As we had data on number of days per week that research participants consumed fruit (average number of fruit servings per day), these data were categorized as dichotomous by using a cutoff point of three days per week. Eighty three percent ate fruits less than 3 days per week and $71.4 \%$ ate vegetables three days per week. On average the subjects were taking fruits 2.14 days per week and vegetables 2.89 days per week. These variables have been described in Table 2 . The study demonstrates that $10 \%$ of respondents were employed at jobs that required vigorous physical activity and $21.6 \%$ at moderate levels of physical activity. The proportions of pathophysiological factors potentially associated with HTN were diabetes (9.9\%), overweight (31.8\%), obesity (15.8\%), and central obesity (52.3\%). The biochemical measurements findings show the mean and SD total triglycerides, cholesterol, HDL, LDL, and fasting blood sugar were $155.3 \pm 61.6,180.7 \pm 47,45.2$ $\pm 10,104.5 \pm 38.2$, and $92.3 \pm 86.2 \mathrm{mg} / \mathrm{DL}$, respectively.

Inferential Analysis:

Initially bivariate analysis was conducted in which hypertensive status increased incrementally with age with the highest prevalence in age group of 55 years and over old (Table 3). Furthermore, this association of age and hypertension was statistically significant. The findings showed no significant association of sex and hypertension. Those who were illiterate were 1.6 times (95\% CI: $1.2-2.1$ ) at greater risk for developing HTN. We found significant associations between the level of income and with hypertension with Odds ratio of 1.6 (95\% CI: 1. - 2.5). Use of snuff was also significantly associated with hypertension (OR=1.56, 95\%CI: $1-$ 2.28). Smoking habits and diet were not significantly associated with HTN. Overweight and obesity were significantly associated with HTN (overweight OR $=2.79,95 \% \mathrm{CI}: 1.40-5.58$ ), (obesity OR $=5.52,95 \%$ CI: 2.69 - 11.32). Central obesity was also significantly associated with hypertension. Those who were HTN had 3.74 (95\% CI: 2.49 - 5.36) times higher odds of being diabetic compared with normal blood pressure. We did not find any significant relationship between level of blood lipids and hypertension in after doing analysis (Table 4). Multivariate analysis (Table 5) demonstrated that older age (more than 40 years) (AOR $=3.05,95 \%$ CI: $2.34-3.98)$, general obesity $(\mathrm{AOR}=1.96,95 \% \mathrm{CI}: 1.36-2.83)$, , central obesity $(\mathrm{AOR}=1.76,95 \% \mathrm{CI}$ : $1.33-2.34)$, diabetic status $(\mathrm{AOR}=1.75,95 \% \mathrm{CI}: 1.10-2.97)$, and diabetes mellitus $(\mathrm{AOR}=0.35,95 \% \mathrm{CI}$ : $0.23-0.55)$ were independently associated with HTN.

\section{DISCUSSION}

Basically this is one of the few published studies on HTN prevalence in Afghanistan. The findings suggest that HTN, which affected more than one third of this sample, is a growing public health challenge in the urban setting of Hirat. However, compared with other regions, it was higher than Kabul and Jalalabad cities [1718]. Female were slightly more than male in our study while the level of hypertension was not different. However the difference in level of hypertension is reported by other studies $[20,28]$ therefore additional studies are needed to test this hypothesis. Results show $5.6 \%$ of respondents were daily smokers while double that number $(10.8 \%)$ were mouth snuff users. It could be due to the low cost of snuff as compared to cigarettes. However both had no association at multivariate level with hypertension. Physical activity and a diet rich in vegetables being protective factors against HTN were not associated with hypertension which could be due to poverty and using similar food by various groups. In addition, obesity and diabetes were found to be independent risk factors for HTN in this study, which is supported by previously published studies [3032]. Results of this study, a baseline understanding of HTN prevalence in the region could be established for Hirat, while further studies and public health programs can be established to compare rates in other geographic settings and evaluate interventions. Screening individuals over the age of 40 is recommended based on findings 
of this study for urban settings of Afghanistan. Furthermore, prevention strategies should focus on risk factors for metabolic syndrome, such as obesity and diabetes. Due to the government's focus on communicable diseases, lesser emphasis is given to non-communicable disease such as hypertension [33]. However lately it has come to focus of government [34]. Change in lifestyle at individual level supported by formal health programs could result in reduction of diseases in future. Screening at primary level could control hypertension and reduce risk because afflicted feel no discomfort until medical crisis such as heart attack, the rupture of a blood vessel in the brain or a stroke - strikes. As a consequence, high blood pressure is often called the silent killer [35] and require regular checking.

\section{ACKNOWLEDGEMENTS}

I would like to thank Afghan National Public Health Institute at Ministry of Public Health and World Health Organization for technical and financial support as well as surveillance staff for data collection and management in the field.

\section{REFERENCES}

[1] WHO. Global status report on noncommunicable diseases 2014. Geneva: World Health Organization; 2014

[2] Abegunde DO, Mathers CD, Adam T, Ortegon M. The burden and costs of chronic diseases in lowincome and middle-income countries. Lancet. 2007 Dec 8;370(9603):1929-38

[3] Kearney PM, Whelton M, Reynolds K, Muntner P, Whelton PK, He J. Global burden of hypertension: Analysis of worldwide data. Lancet. 2005;365(9455):217-223.

[4] Mohan V, Seedat YK, Pradeepa R. The rising burden of diabetes and hypertension in Southeast Asian and African regions: Need for effective strategies for prevention and control in primary health care settings. Int J Hypertens. 2013.

[5] Medscape Cardiology. Hypertension, but not "prehypertension," increases stroke risk: Global prevalence of hypertension may be close to 30\%. 2004; http://www.medscape.com/viewarticle/471536_8

[6] Erem C, Hacihasanoglu A, Kocak M, Deger O, Topbas M. Prevalence of prehypertension and hypertension and associated risk factors among Turkish adults: Trabzon Hypertension Study. J Public Health (Oxf). 2009;31(1):47-58.

[7] Fauci AS, Braunwald E, Kasper DL, et al. Harrison's principles of internal medicine. 17th ed: The McGraw-Hill Companies; 2008.

[8] The American Heart Association. Factors that contribute to high blood pressure. http://www.americanheart.org/presenter.jhtml?identifier $=4650$.

[9] World Health Organization. A global brief on hypertension: Silent killer, global public health crisis. 2013; http://apps.who.int/iris/bitstream/10665/79059/1/WHO_DCO_WHD_2013.2_eng.pdf?ua=1.

[10] Singh RB, Suh IL, Singh VP, et al. Hypertension and stroke in Asia: prevalence, control and strategies in developing countries for prevention. J Hum Hypertens. 2000;14(10-11):749-763.

[11] Unwin N, Setel P, Rashid S, et al. Noncommunicable diseases in sub-Saharan Africa: Where do they feature in the health research agenda? Bull World Health Organ. 2001;79(10):947-953.

[12] Wolf-Maier K, Cooper RS, Banegas JR, et al. Hypertension prevalence and blood pressure levels in 6 European countries, Canada, and the United States. JAMA. 2003;289(18):2363-2369.

[13] Ibrahim MM, Rizk H, Appel LJ, et al. Hypertension prevalence, awareness, treatment, and control in Egypt. Results from the Egyptian National Hypertension Project (NHP). NHP Investigative Team. Hypertension. 1995;26(6 Pt 1):886-890.

[14] Puavilai W, Laorugpongse D, Prompongsa S, et al. Prevalence and some important risk factors of hypertension in Ban Paew District, second report. J Med Assoc Thai. 2011;94(9):1069-1076.

[15] Bener A, Al-Suwaidi J, Al-Jaber K, Al-Marri S, Dagash MH, Elbagi IE. The prevalence of hypertension and its associated risk factors in a newly developed country. Saudi Med J. 2004;25(7):918-922.

[16] World Health Organization. Non-communicable diseases: Hypertension. 2011; http://www.emro.who.int/ncd/hypertension.htm.

[17] Saeed KMI. Prevalence of risk factors for non-communicable diseases in the adult population of urban areas in Kabul City, Afghanistan. CAJGH. 2013;2(2).

[18] Saeed Khwaja Mir Islam, Prevalence of hypertension and associated factors in Jalalabad City, Nangarhar Province, Afghanistan. Central Asian Journal of Global health. 2015;4(1) ISSN 2166-7403 (online) DOI 10.5195/cajgh.2015.134 | http://cajgh.pitt.edu 
[19] Haghdoost AK, BehnamSadeghirad B, Rezazadehkermani M. Epidemiology and heterogeneity of hypertension in Iran: A systematic review. Arch Iranian Med. 2008;11(4):444-452.

[20] Safdar S, Omair A, Faisal U, Hasan H. Prevalence of hypertension in a low income settlement of Karachi, Pakistan. J Pak Med Assoc. 2004;54(10):506-509.

[21] Afghan Public Health Institute Ministry of Public Health (APHI/MoPH) [Afghanistan], Central Statistics Organization (CSO) [Afghanistan], ICF Macro IIoHMRII, [Egypt] WHOROftEMWE. Afghanistan Mortality Survey 2010. Maryland, USA: Calverton; 2011.

[22] Bonita R, deCourten M, Dwyer T, K. J, Winkelmann R. Surveillance of risk factors for noncommunicable disease: the WHO STEPwise approach. Geneva: World Health Organization; 2002.

[23] World Health Organization. Obesity: Preventing and managing the global epidemic; report of a WHO consultation. Geneva: World Health Organization; 2000.

[24] International Diabetes Federation. The IDF consensus worldwide definitions of the metabolic syndrome. 2006; http://www.idf.org/webdata/docs/IDF_Meta_def_final.pdf.

[25] Whitworth JA, World Health Organization, International Society of Hypertension Writing Group. 2003 World Health Organization (WHO)/International Society of Hypertension (ISH) statement on management of hypertension. J Hypertens. 2003; 21(11):1983-1992.

[26] Epi Info [computer program]. Version 7.1.1.14-2013

[27] IBM SPSS Statistics for Windows [computer program]. Version 20.0. Armonk, NY2011.

[28] Yoon SS, Burt V, Louis T, Carroll MD. Hypertension among adults in the United States, 2009-2010. NCHS data brief, no 107. 2012; Hyattsville, MD.

[29] Gudina EK, Michael Y, Assegid S. Prevalence of hypertension and its risk factors in southwest Ethiopia: A hospital-based cross-sectional survey. Integr Blood Press Control. 2013; 6:111-117.

[30] Yadav S, Boddula R, Genitta G, et al. Prevalence of prehypertension, hypertension and cardiovascular risk factors in a Belarus urban population. Indian J Med Res. 2008; 128(6):Indian J Med Res.

[31] Pooja YM. Prevalence of hypertension and its determinants in an urban area of Uttarakhand. AJBPS. 2013; 3(21):12-16.

[32] Prabakaran J, Vijayalakshmi N, VenkataRao E. Prevalence of hypertension among urban adult population (25-64 years) of Nellore, India. Int J Res Dev Health. 2013; 1(2).

[33] The World Bank. NCDs policy brief - Afghanistan. 2011; http://siteresources.worldbank.org/SOUTHASIAEXT/Resources/223546-1296680097256/77074371296680114157/NCD_AF_Policy_Feb_2011.pdf.

[34] Ministry of Public Health Afghanistan. National strategy for prevention and control of noncommunicable

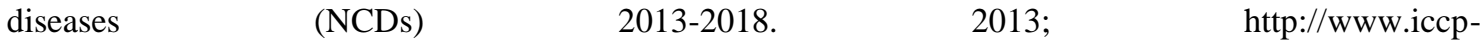
portal.org/sites/default/files/plans/NCDStrategy_Draft_Final_from\%20Af\%20MoH.pdf.

[35] Pamela A, Sytkowski, Ralph B, D’agostino, Albert J. Belanger, William B, Kannel. Secular Trends in Long-Term Sustained Hypertension, Long-Term Treatment, and Cardiovascular Mortality. The Framingham Heart Study 1950 to 1990, Circulation 1996; 93:697-70.

\begin{tabular}{|c|c|c|c|c|c|c|c|}
\hline \multirow[t]{2}{*}{ Variables } & \multirow[t]{2}{*}{ Categories } & \multicolumn{2}{|c|}{ Female } & \multicolumn{2}{|c|}{ Male } & \multicolumn{2}{|c|}{ Total } \\
\hline & & $\mathbf{N}$ & $\%$ & $\mathbf{N}$ & $\%$ & $\mathbf{N}$ & $\%$ \\
\hline \multicolumn{8}{|l|}{ Age } \\
\hline & $25-34$ & 227 & 38.2 & 172 & 32.1 & 399 & 35.3 \\
\hline & $35-44$ & 164 & 27.6 & 124 & 23.2 & 288 & 25.5 \\
\hline & $45-54$ & 120 & 20.2 & 100 & 18.7 & 220 & 19.5 \\
\hline & $55+$ & 83 & 14 & 139 & 26 & 222 & 19.7 \\
\hline \multicolumn{8}{|c|}{ Level of Education } \\
\hline & Illiterate & 394 & 66.7 & 213 & 40 & 607 & 54 \\
\hline & Primary and unofficial & 154 & 26.1 & 226 & 42.4 & 380 & 33.8 \\
\hline & Secondary school & 28 & 4.7 & 45 & 8.4 & 73 & 6.5 \\
\hline
\end{tabular}


Prevalence and Associated Factors of Hypertension in Hirat City Afghanistan-2015

\begin{tabular}{|c|c|c|c|c|c|c|c|}
\hline & High school and over & 15 & 2.5 & 49 & 9.2 & 64 & 5.7 \\
\hline \multicolumn{8}{|l|}{ Work Status } \\
\hline & Official Employees & 32 & 5.7 & 68 & 16.5 & 100 & 10.2 \\
\hline & Private Business & 2 & 0.4 & 87 & 21.1 & 89 & 9.1 \\
\hline & Worker/Farmer & 5 & 0.9 & 179 & 43.3 & 184 & 18.8 \\
\hline & Jobless & 11 & 1.9 & 40 & 9.7 & 51 & 5.2 \\
\hline & Housework & 460 & 81.4 & 1 & 0.2 & 461 & 47.1 \\
\hline & Unable to work & 55 & 9.7 & 38 & 9.2 & 93 & 9.5 \\
\hline \multicolumn{8}{|c|}{ Monthly Income in AFN } \\
\hline & Less than 10000 & 250 & 81.4 & 204 & 84.3 & 454 & 82.7 \\
\hline & More than 10000 & 57 & 18.6 & 38 & 15.7 & 95 & 17.3 \\
\hline \multicolumn{8}{|c|}{ Marital Status } \\
\hline & Single & 16 & 2.7 & 37 & 7 & 53 & 4.7 \\
\hline & Married & 486 & 82.1 & 478 & 90 & 964 & 85.8 \\
\hline & Widow/Widower & 77 & 13 & 6 & 1.1 & 83 & 7.4 \\
\hline & Divorced & 0 & 0 & 1 & 0.2 & 1 & 0,1 \\
\hline & Refused & 13 & 2.2 & 9 & 1.7 & 22 & 2 \\
\hline
\end{tabular}

\begin{tabular}{|c|c|c|c|c|c|c|c|}
\hline \multirow[t]{2}{*}{ Variables } & \multirow[t]{2}{*}{ Categories } & \multicolumn{2}{|c|}{ Female } & \multicolumn{2}{|c|}{ Male } & \multicolumn{2}{|l|}{ Total } \\
\hline & & $\mathbf{N}$ & $\%$ & $\mathbf{N}$ & $\%$ & $\mathbf{N}$ & $\%$ \\
\hline \multicolumn{8}{|c|}{ Cigarette Smoking Status } \\
\hline & No & 559 & 95.2 & 496 & 93.4 & 1055 & 94.4 \\
\hline & Yes & 28 & 4.8 & 35 & 6.6 & 63 & 5.6 \\
\hline \multicolumn{8}{|c|}{ Duration of smoking in years (not equal to above due to non-response or ex smoking) } \\
\hline & $<10$ years & 21 & 56.8 & 32 & 44.4 & 53 & 48.6 \\
\hline & $10-20$ years & 9 & 24.3 & 28 & 38.9 & 37 & 33.9 \\
\hline & $\geq 20$ years & 7 & 18.9 & 12 & 16.7 & 19 & 17.4 \\
\hline \multicolumn{8}{|c|}{ Mouth Snuff Status } \\
\hline & No & 566 & 97.3 & 428 & 80.5 & 994 & 89.2 \\
\hline & Yes & 16 & 2.7 & 104 & 19.5 & 120 & 10.8 \\
\hline \multicolumn{8}{|c|}{ Fruit serving ( days per week) } \\
\hline & $<3$ & 430 & 79.6 & 440 & 86.6 & 870 & 83 \\
\hline & $\geq 3$ & 110 & 20.4 & 68 & 13.4 & 178 & 17 \\
\hline \multicolumn{8}{|c|}{ Vegetables serving (days per week) } \\
\hline & $<3$ & 354 & 63.9 & 408 & 79.5 & 762 & 71.4 \\
\hline & $\geq 3$ & 200 & 36.1 & 105 & 20.5 & 305 & 28.6 \\
\hline \multicolumn{8}{|c|}{ Type of Kitchen Oil } \\
\hline & Liquid & 265 & 45.1 & 238 & 45.2 & 503 & 45.2 \\
\hline & Solid & 207 & 35.3 & 173 & 32.8 & 380 & 34.1 \\
\hline & Both & 113 & 19.3 & 108 & 20.5 & 221 & 19.8 \\
\hline & Refused & 2 & 0.3 & 8 & 1.5 & 10 & 0.9 \\
\hline
\end{tabular}




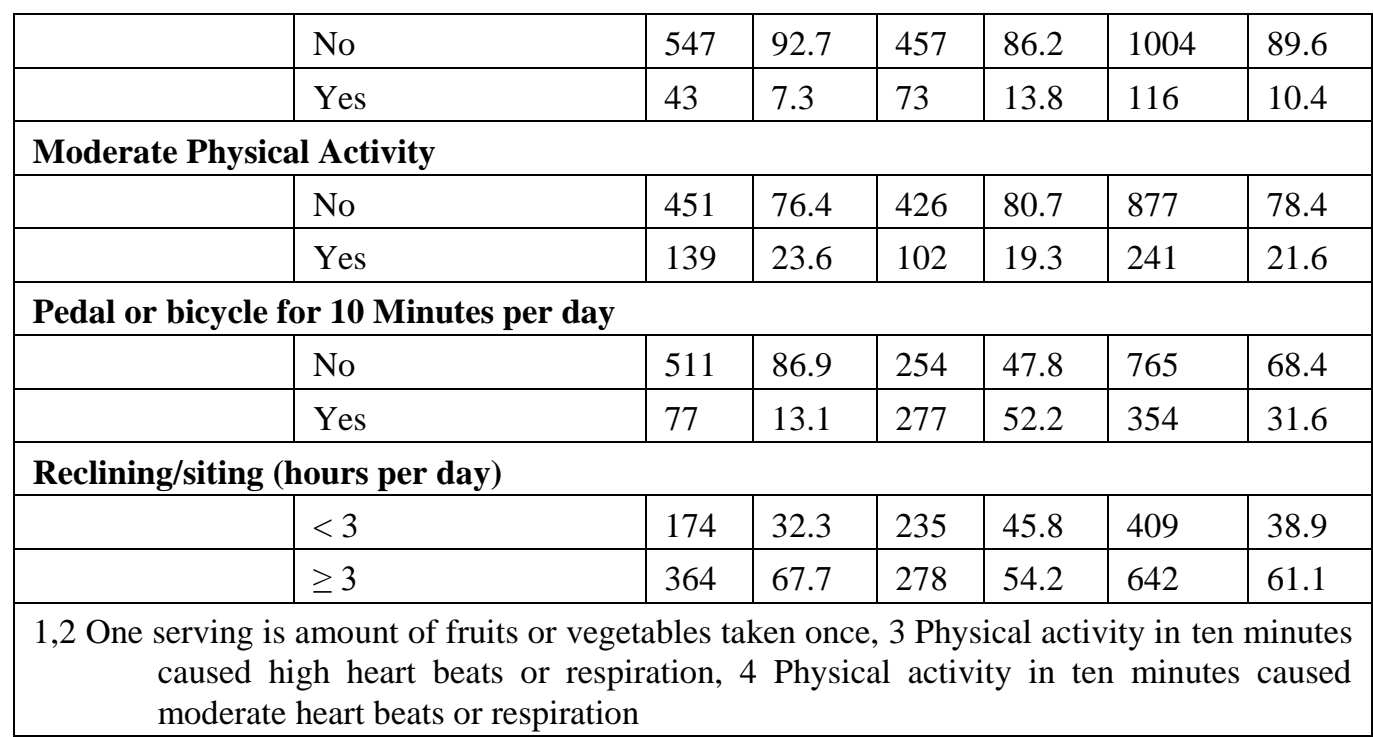

\begin{tabular}{|c|c|c|c|c|c|c|}
\hline Variables & Categories & Normotensive & Hypertensive & Odds Ratio & CI 95\% LL & CI 95\% UL \\
\hline \multicolumn{7}{|c|}{ Age in years } \\
\hline & $25-34$ & $321(80.5)$ & $78(19.5)$ & 1 & \multicolumn{2}{|l|}{ Reference } \\
\hline & $35-44$ & $199(69.1)$ & $89(30.9)$ & 1.841 & 1.295 & 2.616 \\
\hline & $45-54$ & $122(55.5)$ & $98(44.5)$ & 3.306 & 2.299 & 4.753 \\
\hline & 55 and over & $85(38.3)$ & $137(61.7)$ & 6.633 & 4.597 & 9.571 \\
\hline \multicolumn{7}{|l|}{ Sex } \\
\hline & Female & $381(64.1)$ & $213(35.9)$ & 1 & \multicolumn{2}{|l|}{ Reference } \\
\hline & Male & $346(64.7)$ & $189(35.3)$ & 0.977 & 0.766 & 1.247 \\
\hline \multicolumn{7}{|c|}{ Level of education } \\
\hline & Illiterate & $361(59.5)$ & $246(40.5)$ & 1.63 & 1.27 & 2.1 \\
\hline & Literate & $365(70.6)$ & $152(29.4)$ & 1 & \multicolumn{2}{|l|}{ Reference } \\
\hline \multicolumn{7}{|c|}{ Monthly income (Afghanis) } \\
\hline & $\leq 150$ USD & $304(67)$ & $150(33)$ & 1 & \multicolumn{2}{|l|}{ Reference } \\
\hline & $\geq 150$ USD & $53(55.8)$ & $42(44.2)$ & 1.606 & 1.024 & 2.518 \\
\hline \multicolumn{7}{|l|}{ Snuff Use } \\
\hline & No & $652(65.6)$ & $342(34.4)$ & 1 & \multicolumn{2}{|l|}{ Reference } \\
\hline & Yes & $66(55)$ & $54(45)$ & 1.56 & 1.064 & 2.287 \\
\hline \multicolumn{7}{|l|}{ Smoking } \\
\hline & No & $679(64.4)$ & $376(35.6)$ & 1 & Reference & \\
\hline & Yes & $43(68.3)$ & $20(31.7)$ & 0.84 & 0.487 & 1.449 \\
\hline \multicolumn{7}{|c|}{ Fruits serving days per week } \\
\hline & $<3$ days & $573(65.9)$ & $297(34.1)$ & & & \\
\hline & $\geq 3$ days & $109(61.2)$ & $69(38.8)$ & 1.221 & 0.876 & 1.703 \\
\hline \multicolumn{7}{|c|}{ Vegetables serving days per week } \\
\hline & $<3$ days & $507(66.5)$ & $255(33.5)$ & 1 & \multicolumn{2}{|l|}{ Reference } \\
\hline & $\geq 3$ days & $187(61.3)$ & $118(38.7)$ & 1.255 & 0.953 & 1.652 \\
\hline Strong Phy & sical Activity & & & & & \\
\hline
\end{tabular}




\begin{tabular}{|c|c|c|c|c|c|}
\hline No & $651(64.8)$ & $353(35.2)$ & 1 & Reference & \\
\hline Yes & $70(60.3)$ & $46(39.7)$ & 1.212 & 0.817 & 1.797 \\
\hline \multicolumn{6}{|c|}{ Moderate Physical Activity } \\
\hline No & $570(65)$ & $307(35)$ & 1 & Reference & \\
\hline Yes & $149(61.8)$ & $399(35.7)$ & 1.146 & 0.854 & 1.539 \\
\hline \multicolumn{6}{|c|}{ Sedentary lifestyle in hours daily } \\
\hline$<3$ hours & $264(54.5)$ & $145(35.5)$ & 1 & Reference & \\
\hline$\geq 3$ hours & $420(65.4)$ & $222(34.6)$ & 0.962 & 0.742 & 1.248 \\
\hline
\end{tabular}

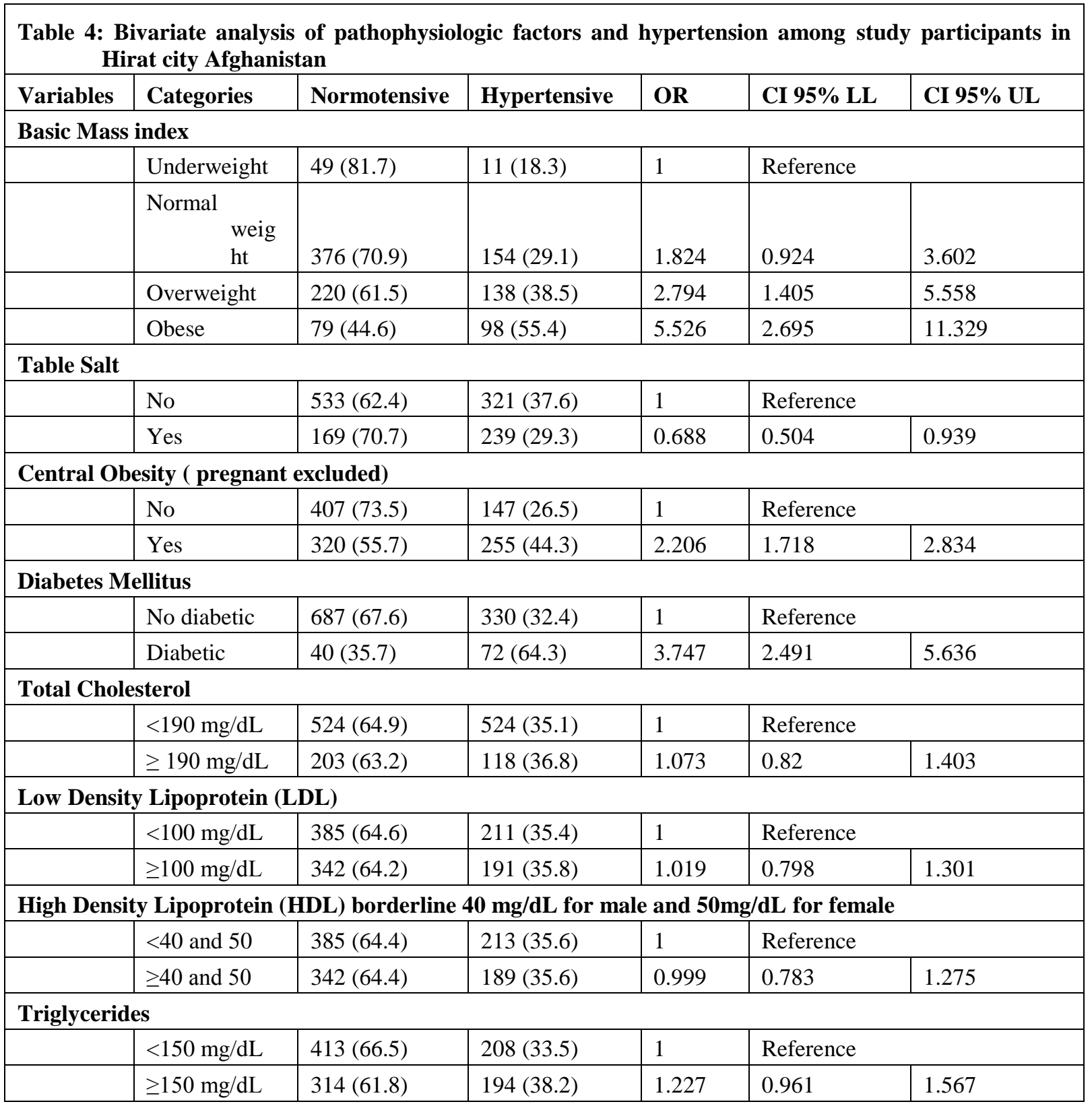

\begin{tabular}{|c|c|c|c|c|c|}
\hline Variables & Categories & Adjusted Odds Ratio & CI 95\% LL & CI 95\% UL & P Value \\
\hline
\end{tabular}




\begin{tabular}{|c|c|c|c|c|c|}
\hline \multicolumn{6}{|l|}{ Age } \\
\hline & $<40$ years & 1 & \multicolumn{3}{|l|}{ Reference } \\
\hline & $>40$ years & 3.055 & 2.343 & 3.982 & $\mathrm{PV}<001$ \\
\hline \multicolumn{6}{|c|}{ Obesity General } \\
\hline & No & 1 & \multicolumn{3}{|l|}{ Reference } \\
\hline & Yes & 1.965 & 1.362 & 2.834 & $\mathrm{PV}<001$ \\
\hline \multicolumn{6}{|c|}{ General Obesity } \\
\hline & No & 1 & \multicolumn{3}{|l|}{ Reference } \\
\hline & Yes & 1.767 & 1.333 & 2.342 & $\mathrm{PV}<001$ \\
\hline \multicolumn{6}{|c|}{ Diabetes Mellitus } \\
\hline & No & 1 & \multicolumn{3}{|l|}{ Reference } \\
\hline & Yes & 0.359 & 0.233 & 0.555 & $\mathrm{PV}<001$ \\
\hline
\end{tabular}

